\title{
A MODEL OF THE MODERATING EFFECTS OF PRIOR KNOWLEDGE, LEVEL OF EDUCATION, AND INCOME LEVEL ON THE USE OF EXTRINSIC QUALITY CUES ON CONSUMERS' QUALITY ASSESSMENTS
}

\author{
Alejandro Zegarra and Corina Negru
}

\begin{abstract}
The present study follows Steenkamp's relativistic concept on the effects of personal variables on the relationship between extrinsic cues and perceived quality. It aims to discuss the moderating effects of prior knowledge, level of education, and income level on the use of price, brand name, warranty, country of origin, and advertising on consumers' quality assessments. A theoretical framework is proposed and several hypotheses are formulated.
\end{abstract}

Keywords: Perceived Quality, Extrinsic Quality Cues, Intrinsic Quality Cues. 